\title{
Interactive Theory of Breastfeeding: creation and application of a middle-range theory
}

\author{
Teoria Interativa de Amamentação: elaboração e aplicação de uma teoria de médio alcance \\ Teoría Interactiva de Lactancia: elaboración y aplicación de una teoría de mediano alcance
}

\section{Cândida Caniçali Primo', Marcos Antônio Gomes Brandão"}

'Universidade Federal do Espírito Santo, Health Sciences Center, Postgraduate Program in Nursing. Vitória, Espírito Santo, Brazil.

"Universidade Federal do Rio de Janeiro, Ana Nery School of Nursing, Postgraduate Program in Nursing. Rio de Janeiro, Brazil.

How to cite this article:

Primo CC, Brandão MAG. Interactive Theory of Breastfeeding: creation and application of a middle-range theory. Rev Bras Enferm [Internet]. 2017;70(6):1191-8. DOI: http://dx.doi.org/10.1590/0034-7167-2016-0523

\section{Submission: 11-09-2016 Approval: 1-16-2017.}

\begin{abstract}
Objective: To describe a breastfeeding theory based on King's Conceptual System. Method: Theoretical study that used analysis of concept, assertion synthesis, and derivation of theory for the creation of a new theory. Results: King's system components were associated with elements of the breastfeeding process and a middle-range theory was created, which describes, explains, predicts, and prescribes breastfeeding by analyzing factors that precede and affect it, as well as their consequences on the breastfeeding process. Conclusion: The Breastfeeding Interactive Model is abstract enough to be applied in different social, cultural, political, and economic contexts, because it conceptualizes breastfeeding in systemic, dynamic, and procedural aspects. Based on a conceptual model of nursing, it contributes to the scientific construction of the subject; however it can also potentially be applied by other professionals involved in breastfeeding assistance.
\end{abstract}

Descriptors: Nursing Theory, Breastfeeding; Mother-Child Relations; Weaning; Women's Health; Child Health.

\section{RESUMO}

Objetivo: Descrever uma teoria de amamentação baseada no Modelo Conceitual de Sistemas Abertos de Imogene King. Método: Estudo teórico, que utilizou análise de conceito, síntese de afirmação e derivação de teoria para a elaboração da teoria. Resultados: Articularam-se os componentes do Modelo de King com os elementos do processo de amamentação e elaborou-se uma teoria de médio alcance, que descreve, explica, prediz e prescreve a amamentação, examinando os fatores que antecedem e influenciam, bem como as consequências no processo de amamentar. Conclusão: A Teoria Interativa de Amamentação é abstrata o suficiente para ser aplicada nos diferentes contextos sociais, culturais, políticos e econômicos, pois conceitua a amamentação na dimensão sistêmica, dinâmica e processual. Sua base em um modelo conceitual de Enfermagem contribui para a construção da ciência na disciplina, contudo tem potencial para aplicação por outros profissionais envolvidos na assistência à amamentação.

Descritores: Teoria de Enfermagem; Aleitamento Materno; Relações Mãe-Filho; Desmame; Saúde da Mulher; Saúde da Criança.

\section{RESUMEN}

Objetivo: Describir una teoría de lactancia basada en el Modelo Conceptual de Sistemas Abiertos de Imogene King. Método: Estudio teórico, que utilizó análisis de concepto, síntesis de afirmación y derivación de teoría para la elaboración de la teoría. Resultados: Se articularon los componentes del Modelo de King con los elementos del proceso de lactancia, elaborándose una teoría de mediano alcance que describe, explica, predice y prescribe la lactancia, examinando los factores antecedentes con influencia. Así como las consecuencias del proceso de lactancia. Conclusión: La Teoría Interactiva de Lactancia es lo suficientemente abstracta como para aplicarla en los diferentes contextos sociales, culturales, políticos y económicos, pues conceptualiza la lactancia en su dimensión sistémica, dinámica y procesual. Su base en un modelo conceptual de Enfermería contribuye a la construcción científica en la disciplina, aunque cuenta con potencial para su aplicación por otros profesionales involucrados en la atención de la lactancia.

Descriptores: Teoría de Enfermería; Lactancia Materna; Relaciones Madre-Hijo; Destete; Salud de la Mujer; Salud del Niño.

\section{CORRESPONDING AUTHOR Cândida Caniçali Primo E-mail: candida.primo@ufes.br}




\section{INTRODUCTION}

The knowledge of nursing has evolved differently at times, with specific characteristics and orientations, where the $21 \mathrm{st}$ century is the "era of theory use"(1). However, this latest evolutionary stage seems to be slow. This assertion is sustained in a review study in high impact journals, and it found that progress in the use of nursing theories after the 2000s compared to the 1990s, but this increase was not significant ${ }^{(2)}$.

In daily nursing care, theories serve as an organizing reference or structure that works as a symbolic representation of aspects of reality. Its purpose is to describe, explain, predict, or prescribe conditions or relations between phenomena ${ }^{(3)}$. Indeed, the ability to apply theory to clinical practice is related to its quality or validity attributes, and also to its abstraction level. In terms of abstraction and scope, the more abstract and wide is defined as being a grand theory. The level below, which is more concrete and less comprehensive, is the middle-range level. Today, in the "era of theory use," one of the priorities of nursing science is the development of middle-range theories that are significant and applicable to clinical practice; they contain a limited number of variables and relations that are subject to testing, and they also provide enough generalities to be scientifically relevant ${ }^{(4)}$.

Considering and acknowledging the epistemological value of theories for nursing, this study is about the proposal of a middle-range theory regarding breastfeeding.

There is substantial knowledge in the scientific literature about the experiences and circumstances that affect women's choice for breastfeeding, but this process is more complex than describing the experiences and conditions of women who can or cannot breastfeed ${ }^{(5-6)}$. Therefore, this event must be studied in all its complexity, and factors that affect its beginning, maintenance, and completion must be described and explained.

Although publications on breastfeeding can be found in journals, no theories on this process were found after a broad literature review. Two articles on concept analysis that were found were closer to a theoretical construct and they described breastfeeding as a dynamic relationship between mother and child $^{(7-8)}$. This knowledge gap encouraged the development of a middle-range theory based on an interactionist conceptual model. King's Conceptual System ${ }^{(9)}$ was then selected as a theoretical reference from which to derive the proposed theory.

We worked on the assumption that King's theoretical framework could ground a middle-range theory oriented to care of women, children, and family during breastfeeding, and its interactionist features would tend to make dialogs more sensitive to each subject's perception in an easier manner, and overcome purely technical and restricted practices in care meetings. In view of these issues, the objective of this article is to describe the development of a breastfeeding theory that focuses on factors that affect breastfeeding.

\section{METHOD}

\section{Ethical aspects}

Due to the nature of this theoretical research and the nonparticipation of human beings, submission to the Research Ethics Committee was exempted.

\section{Theoretical framework}

This study used King's Conceptual System ${ }^{(9)}$ to develop the Interactive Theory of Breastfeeding. King's Conceptual System was selected, which is open and interrelated, and composed of three interactive systems: personal; interpersonal; and social. The concept of a personal system includes seven aspects: perception; self; body image; growth; development; time; and space. An interpersonal system is composed of human beings who interact in this system and it includes the concepts of interaction, communication, transaction, role, and stress. A social system is formed by the combination of interpersonal systems with the following relevant concepts: organization; authority; power; status; and decision-making.

\section{Type of study}

This is a theoretical or basic study, of a descriptive-exploratory nature, with a qualitative approach.

\section{Methodological procedures}

Three methodological strategies were followed to develop the theory: concept analysis; synthesis of scientific literature; and derivation of theory ${ }^{(10)}$.

The concept analysis searched for concepts of breastfeeding found in the literature. Six of the eight steps were taken: concept selection; determination of objects for concept analysis; identification of possible uses of the concept; determination of defining or critical attributes; identification of background and consequences of the concept; and definition of empirical indicators ${ }^{(10)}$.

To help in the analysis, an integrative review of the literature was carried out in May 2015 in the Latin American and Caribbean Center on Health Sciences Information database (LILACS) and in the Medical Literature Analysis and Retrieval System online database (MEDLINE), with the descriptors: "Breastfeeding" and "mother and child relations," and the following inclusion criteria: original articles published between 2010 and 2014 in Portuguese, English, or Spanish. Two hundred fifty-one articles were found on MEDLINE and 28 on LILACS; after summaries were reviewed and criteria were applied, 68 articles were selected for full reading, and 52 of these were submitted to all steps of concept analysis. The guiding questions of the review with the goal of the identification of uses, background, and consequences of the concept were: What conditions affect the beginning of breastfeeding? What are the consequences of breastfeeding?

A methodological strategy of synthesis attempted to detail the relationship between two or more evidence-based concepts. The sources of evidence were the qualitative and quantitative studies selected in the literature review. By means of synthesis, theoretical statements of relational and non-relational types were drawn up. A non-relational assertion corresponds to a theoretical or operational definition of concept; a relational assertion expresses some kind of relationship between two or more concepts and they can confirm an association or causality ${ }^{(10)}$.

The third strategy was the derivation of theory, that is, a focused and creative path to draw up theories in a new field, for which some skills are required: an ability to see the analogical aspect in two contexts or different fields of interest, and an ability to redefine and transpose the content and/or structure of a context or 
field to another ${ }^{(10)}$. Contents were derived from King's Conceptual System for the construction of a middle-range theory.

\section{RESULTS}

A theory has different components such as purpose, concepts, statements, conceptual framework, assumptions, and propositions ${ }^{(3)}$. Results are presented below and they describe each component of the proposed theory.

The fundamental purposes of the Interactive Theory of Breastfeeding are to describe and explain this phenomenon by analyzing the factors that precede and affect the breastfeeding process. When the theory describes the consequences of breastfeeding, it provides elements that can contribute to predicting the results and the dynamic interactivity of breastfeeding, and also contribute to prescribing actions to ensure that the different benefits of breastfeeding are achieved.

Concepts of the Interactive Theory of Breastfeeding: Based on the analysis of the concept of breastfeeding, the following theoretical concepts were proposed: mother-child dynamic interaction; woman's biological conditions; child's biological conditions; woman's perception; child's perception; woman's body image; space for breastfeeding; mother's role; organizational systems for the protection, promotion and support of breastfeeding; family and social authority; woman's decision making; stress; and time of breastfeeding.

Non-relational statements of concepts: After the identification of the main concepts, non-relational statements were drawn up for each concept of the theory, as described below:

The dynamic interaction between mother and child involves perception, judgment, action and reaction during positioning, latching, and suckling for the mutual objective, which is breastfeeding. This dynamic interaction is ensured by verbal and non-verbal communication between mother and child.

A woman's biological conditions are defined as the biological characteristics and functions that are suitable to breastfeeding. They occur at the levels of cellular, molecular, and behavioral activities that include the breast anatomy and mother's milk production.

A child's biological conditions are defined as biological characteristics and functions that are suitable to breastfeeding. They occur at the levels of cellular, molecular, and behavioral activities that include the anatomy and physiology of newborns' stomatognathic system.

The woman's perception of breastfeeding is the process by which information obtained by the senses and memory are organized, interpreted, and transformed. This perception varies, because each woman has a different background, in terms of knowledge, social and economic condition, skills, emotions, needs, beliefs, culture, and goals.

A child's perception of breastfeeding is the process by which information obtained by the senses and memory are organized, interpreted, and transformed. This perception refers to sensations felt by the child during breastfeeding.

A woman's body image is the way each woman perceives her body during breastfeeding and the reaction of others to her figure; it is dynamic, personal, and subjective.
Space for breastfeeding is defined as a personal, subjective, individual, and situational universe that depends on relationships and that is based on the woman's perception of breastfeeding.

The mother's role is a social behavior that the woman is expected to follow when she becomes a mother, and it implies her relationship with the child and breastfeeding; thus she acquires the rights and responsibilities of this new social role.

Organizational systems for the protection, promotion, and support of breastfeeding are composed of the family, the community, and society, and some resources are used in order to achieve these objectives.

Family and social authority is a transactional process in which the values, background, and perceptions of each member who takes part in the breastfeeding process have an influence on the control, direction, and change in women's behavior with regard to breastfeeding.

Woman's decision making is a dynamic and systematic process, by means of which they choose to breastfeed among other options.

Stress is a dynamic state that is increased or reduced by the action of stressful factors that results from the interactions between the woman, the child, and the environment. It involves the exchange of energy and information between the woman, the child, and the environment for the regulation and control of stressful factors in breastfeeding, which can be within or outside the mother-child pair.

Internal stressful factors in breastfeeding can be negative perceptions of women, inadequate biological conditions of women and children, body image, and the conflictive role as a mother. The external stressful factors are: an inadequate space; nonexistent or ineffective organizational systems for protection, promotion, and support; and family or social authority that is opposed to breastfeeding.

Stress is related to intrinsic and extrinsic factors, which can be matters related to women that sometimes create an unsatisfactory relationship with their children, or related to children who cannot establish this relationship with their mothers.

The time of breastfeeding is defined as the duration between events, and it is experienced by each woman in a unique way. This time is divided into two types: the length of the breastfeeding process, which includes the time gap between the first feeding and weaning, and the length of each feeding. The length of exclusive breastfeeding recommended by national and international organizations is six months to two years when it is complemented. The length of feeding is the time required to satisfy the child's needs, and it can vary from child to child. The breastfeeding length is determined by the mother-child dynamic interaction.

The concepts and non-relational statements built by means of analysis and synthesis strategies make up the content of the Interactive Theory of Breastfeeding.

Schematic organization of relational statements in the dynamic process of breastfeeding: By means of theoretical derivation, King's Conceptual System was used in the scope of the human interaction process (Figure 1) as a modeling structure for the organization of the breastfeeding dynamic process. 


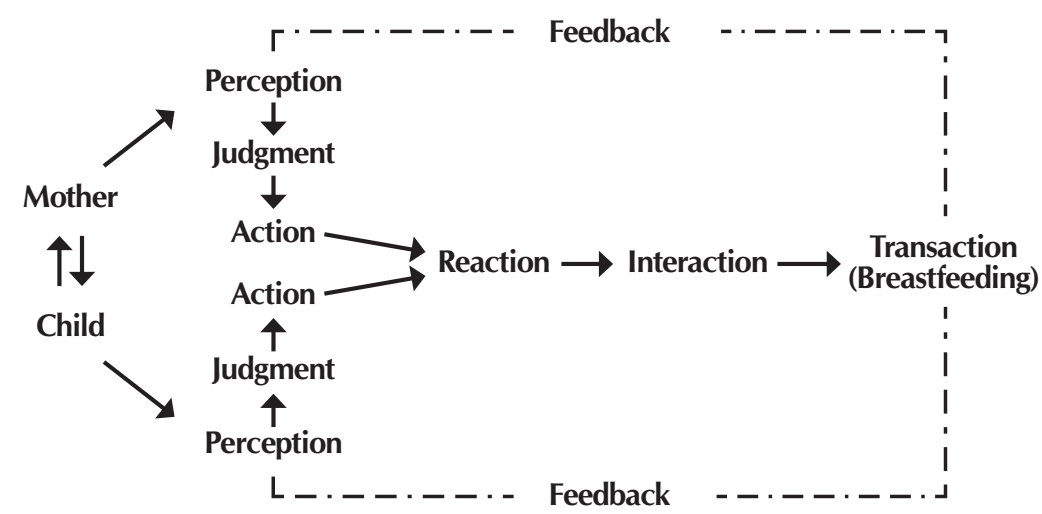

Figure 1 - Process of mother-child interaction to perform breastfeeding derived from King's interaction-transaction process (inclusion of breastfeeding as "transaction")

To King, the process represented in Figure 1 includes the nurse and the client and it would be the nursing process, called by the nurse as "interaction transaction process" ${ }^{\text {"(9). In }}$ the Interactive Theory of Breastfeeding, the interaction process is focused on the mother and the child.

By deriving the flow of King's interaction-transaction process, we can say that, in the context of breastfeeding, the interaction between mother and child is dynamic and includes elements such as perception, judgment, and action and reaction between mother and child. These elements are essential to achieve the mutual goal (transaction), it is the breastfeeding.

In the original model, interaction is a process of exchange (action and reaction) that takes place when the nurse and the client are in liaison, when they perceive each other and make a judgment about each other ${ }^{(9)}$. As for the Interactive Theory of Breastfeeding, because the main subjects are those who make up the pair, interaction is a process of exchange that takes place when mother and child are in liaison. In this exchange process, the people involved can reveal what they think and feel and how they perceive each other. In view of this concept, interaction is characterized by action and reaction, and it is mediated by different forms of communication. Mothers and children form personal systems with their own subjectivity and complexity.

These dynamics are ensured by exchanges (physical, chemical, biological, and sensory) in verbal and non-verbal communication between mother and child. There is a flow of information which consists of the sensory, linguistic, neurophysiological, and subjective elements that make up the content of "perception." A woman's perception guides her judgment, which leads her to make decisions on the action to perform. Thus, the transaction takes place within a process of perception, judgment, and actionreaction, and it is implemented when breastfeeding is performed (transaction).

Judgments are within the context of women's evaluation of the child and of themselves, and they tend to include issues of the success or failure of feedings, of meeting the needs of and impressions about the child's response. Action is a sequence of conducts of interaction between people, which include: 1) mental action-acknowledgment of current conditions; 2) physical conditions; and 3) mental action to have control over events and physical actions in an attempt to achieve the goals. Transaction occurs in concrete situations in which human beings are actively participating in events, and this active participation in the attempt to achieve the goals leads to an exchange between individual $s^{(9)}$.

Theory core concept - breastfeeding as a transactional concept: The concept of interaction is a core concept to Interactive Theory of Breastfeeding, because this mother-child interaction takes place at the moment of breastfeeding, when the mother interacts with the child's personal system and with other interpersonal and social systems so that breastfeeding begins, continues, and ends. The development of the interaction concept requires the understanding of roles, where one person's role is defined according to the other person's role, such as the roles of mother and child ${ }^{(9)}$. In other words, for the interaction to take place, roles must be clearly defined. In this theory, the mother's role can be played by a woman who takes over this role, regardless of whether she is the biological mother or not.

Interaction causes transaction, which is a relational statement of causality. Transaction takes place as soon as mother and child perceive and exchange (action and reaction) satisfactorily; that is, when there is a mother-child interaction. In this way, there will only be a transaction for breastfeeding when there is interaction and exchange between mother and child.

In view of this, a definition of breastfeeding that encompasses the transactional feature derived from the conceptual model was drawn up. Thus, "breastfeeding is a process of dynamic interaction in which mother and child interact with each other and with the environment in order to obtain the benefits of mother's milk, which is directly provided from the breast to the child and which is a unique experience every time".

Conceptual framework of the Interactive Theory of Breastfeeding: During the derivation of the theory that shaped the Interactive Theory of Breastfeeding, the conceptual framework of King's Conceptual System was assessed ${ }^{(9)}$. In an attempt to transpose the theoretical framework from one field to another with creativity and scientific knowledge of breastfeeding, we were able to see that it creates a hierarchy between the concepts that form the theory, as seen in Figure 2.

Based on evidence taken from a literature review, empirical data on breastfeeding suggest that "woman's and child's biological conditions", "woman's and child's perception," and "woman's decision making" are essential for breastfeeding to occur and they have a direct and necessary influence. Biological conditions include the breasts' anatomy, production of milk, and children's stomatognathic system anatomy and physiology. A woman's perception of breastfeeding varies, because it depends on knowledge, social and economic conditions, skills, emotions, needs, beliefs, culture, and the objectives of each woman. A child's perception refers to senses (taste, sight, touch, smell, and hearing) perceived during breastfeeding that are stimuli related to the process. 
A woman's decision making is more comprehensive, because it is a dynamic and systematic process by means of which they choose to breastfeed among other options. At each feeding experience, women make more specific decisions that characterize the act of breastfeeding. It is assumed that women's decision to continue interacting with the child, resulting in breastfeeding, is rebuilt after each experience. So we can see in Figure 2 that these three concepts involve the dynamic process of breastfeeding in a more proximal way.

The Interactive Theory of Breastfeeding postulates that some concepts have an influence on breastfeeding, modulating it in a more distal way, and they are: woman's body image; space for breastfeeding; mother's role; organizational systems for the protection, promotion, and support of breastfeeding; and family and social authority. Therefore, they are more likely to be closely linked to or strongly influenced by the social system, according to King's Conceptual System (Figure 2).

As for the level of the interaction process itself, the existence of two relevant concepts was considered: time of breastfeeding and stress. Time is directly influenced and modulated by the motherchild dynamic interaction during breastfeeding. This interaction affects the duration of each feeding and the continuity or discontinuation of exclusive breastfeeding after the sixth month, which is affected by the introduction of new food when the child is six months old or less. Stress is a dynamic state that is increased or reduced by the action of stressful factors resulting from the interactions between the woman, the child, and the environment.

Stress affects mother and child interaction, because depending on the level of stress of each individual, communication and interaction between them may not occur properly and may impair the transaction achievement; that is, breastfeeding does not happen (Figure 2).

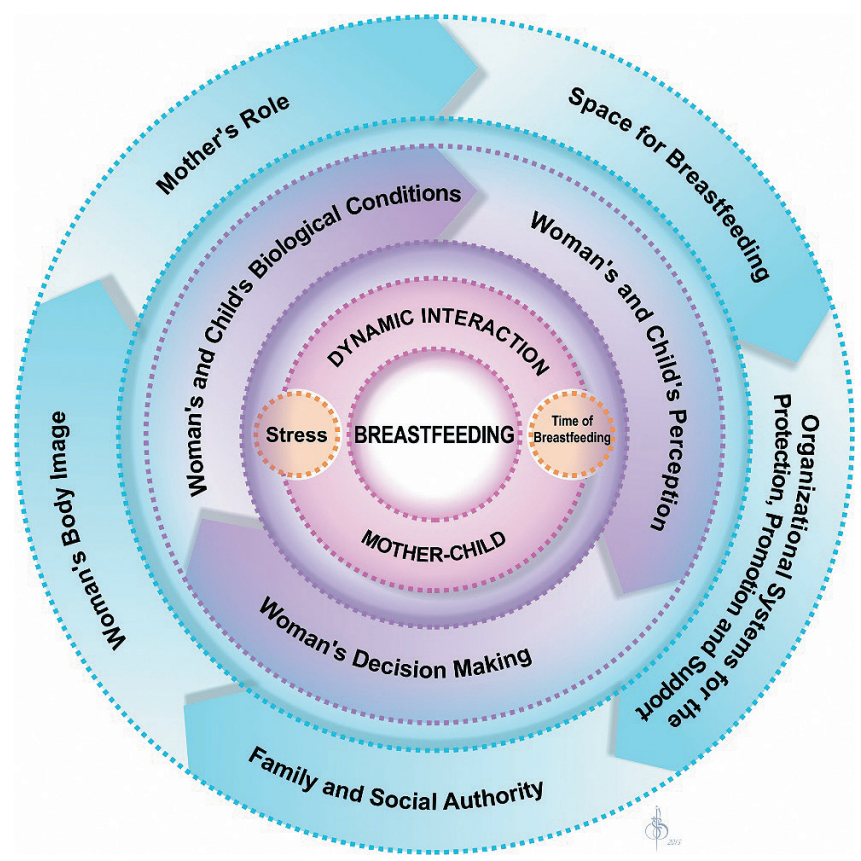

Figure 2 - Conceptual framework of the Interactive Theory of Breastfeeding
Assumptions and propositions: Assumptions are principles that are accepted as true without evidence, on which the proposed theory was based. Propositions are statements that describe the relationship between concepts within the theory and, as such, they allow for a large variety of hypotheses to be empirically tested $^{(4)}$. By using King's Conceptual System as a theoretical basis, it is argued that this middle-range theory is in line with a vision of mutual interaction; it is based on the assumptions of the Open Systems Model in order to set out its own assumptions:

- The conceptual framework of the Interactive Theory of Breastfeeding is the theoretical representation of an open, interrelated, and recurring system that represents the breastfeeding process and is composed of 11 concepts

- Its purpose is to describe and explain the breastfeeding process as being interactive and systemic

- Individuals are complex, social, spiritual, holistic, conscious, and rational beings who have the ability to think, understand, make decisions, and choose alternatives to achieve their goals.

- Individuals differ in their needs, desires, and objectives, because they are unique, with different perceptions, values, cultures, and beliefs that are transmitted from one generation to another; consequently they can vary from one individual to another, one family to another, and one society to another

- Individuals do not know themselves completely and they consciously interact with each other, with objects, and with the environment; their perceptions, judgments, and actions can be incongruous

- Within this system, the individuals are the woman, the child, family members, health professionals, and society.

Proposals of the Interactive Theory of Breastfeeding include:

- Breastfeeding is a dynamic process in which mother and child interact with each other and with the environment in order to obtain the benefits of mothers' milk, which is directly provided from the breast to the child and which is a unique experience every time

- The mother-child dynamic interaction is influenced by and also interferes with the woman's and child's perceptions; in the woman's and child's biological conditions; in the woman's body image; in space for breastfeeding; in mother's role; in organizational systems for the protection, promotion, and support of breastfeeding; in family and social authority; and in women's decision making

- The mother-child dynamic interaction modulates the time of breastfeeding and the stress

- If perception is negative, if biological conditions are inadequate, or if there is a conflict in their roles, motherchild interaction will be stressful

- If the space is inadequate; if the mother's body image is not satisfactory; if organizational systems for protection, promotion, and support are nonexistent or ineffective; or family or social authority is opposed to breastfeeding, there may be stress in the mother-child interaction 
- If mother and child expectations and needs match, breastfeeding will be successful

- If breastfeeding succeeds, there will be satisfaction

- If breastfeeding succeeds, as a consequence, there will be benefits to the mother's and child's health and to society

- The transactional achievement of breastfeeding reduces the stress of both mother and child

- The perceptions, judgments, and actions of mother and child when congruent produce a transaction

- The achievement of transaction between mother and child represents the fulfillment of the breastfeeding process

\section{DISCUSSION}

Theories explain, in their own way, the practice using concepts that express the development of actions and clarify the perspective of professional factors, with the objective of consolidating nursing as a science and art in the health field ${ }^{(11)}$. Theories are generally constructed to express a new idea or a new perspective about a phenomenon of interest, and this is the primary way of building a new body of knowledge that is specific to nursing(3).

The Interactive Theory of Breastfeeding conceptualizes breastfeeding in a systemic, dynamic, and procedural dimension. The other proposed concepts are multidimensional and they interact, and this affects the dynamic concept of breastfeeding. We have tried to make a selection of concepts that were essential to the theory building ${ }^{(4,10)}$ in an innovative way, even though the selection of a larger number of concepts was possible.

There is a debate on the conceptual "position" of breastfeeding. One approach argues that it is more appropriate to place the concept of breastfeeding in a nutritional dimension, as an act of child nutrition. Another approach places it in the relational dimension. We understand that considering breastfeeding as nutrition diminishes this phenomenon, relegating the benefits to specialization, particularization, and determination. However, this diminishment could relegate breastfeeding to a secondary role in more comprehensive and relevant fields or systems-for instance, the roles of culture, social status, autonomy for decision-making, and social gains or costs.

In the organization of the middle-range theory, empirical indicators and a definition ${ }^{(10)}$ that encompass the multidimensional feature of breastfeeding must be produced. Therefore, the proposed definition includes the dynamic interaction (changing and capable of being unique in every breastfeeding event), and states that breastfeeding goes beyond personal and interpersonal systems, projecting itself to interact socially and with the environment. The environment is the locus where the pair is found, as well as the conditions of the surroundings where the mother and child's personal and interpersonal systems interact ${ }^{(9)}$.

It is currently known that material, social, cultural, and political conditions shape our lives and behaviors, and they have a strong influence on health ${ }^{(12)}$. Social determinants affect child mortality rate because they structure other determinants that relate to these indicators ${ }^{(13)}$. Given the strength of interpersonal and social aspects, the Interactive Theory of
Breastfeeding is a theoretical framework that is concordant with the models of social determinants of health.

Influenced by personal, interpersonal, or social factors, women report that during breastfeeding they feel pleasure and happiness, but they are also concerned with their milk supply, with sagging breasts, and embarrassed by breastfeeding in public ${ }^{(14-16)}$. The woman's perception of breastfeeding is based on their emotions, their backgrounds, personal, family, and social experiences with breastfeeding, as well as on skills, knowledge, beliefs, and clichés learned throughout their lives, thus varying between women $^{(15,17-18)}$. To many of them, breastfeeding is an act of love, of divine gift, but it also requires a sense of duty and obligation.

Therefore, some women fear being considered as "bad" or "careless" mothers; they breastfeed so as not to feel guilty and prefer not to reveal their feelings. Women who play their role as mothers and try, despite everything, to preserve their autonomy, even if it is limited, are able to decide when to begin breastfeeding and whether to maintain it or not $t^{(5,15)}$.

To be aware of the most influential individuals in the nursing mother's social network and to understand the interaction between these people and the woman during breastfeeding is essential, because this practice is subject to multiple influences, positive or negative, from relatives, friends, neighbors, and health professionals ${ }^{(19)}$. Grandparents and female figures who have already experienced motherhood and breastfeeding, as well as partners, are the most influential individuals. Support from friends, members of the church, and health professionals is also important, because it contributes to improve mothers' selfconfidence and assurance to begin and to keep breastfeeding ${ }^{(20)}$.

Women's decision to begin breastfeeding and its continuity after each feeding is a complex process that is affected by different factors, among which are: awareness of the benefits of breastfeeding; receiving family, social, and professional support; having a positive personal experience and family tradition; and the desire and personal choice to breastfeed ${ }^{(5-6)}$. However, when women receive negative influences that are opposed to breastfeeding, they can choose other ways to feed their children, either by not beginning to breastfeed or by discontinuing it prematurely.

Nurses can identify the factors that interfere in breastfeeding completion so as to act in a more interactive and systemic way by using the theory concepts. There is a particular contribution to the identification of nursing diagnoses that are more specific to the breastfeeding process. For instance, woman's decision making, when it is autonomous, allows the professional to diagnose the "adequate decision-making process for breastfeeding." On the other hand, when autonomy is restricted, decision-making might not be complete, which can result in the diagnostic hypothesis of "risk to an inadequate decision-making process for breastfeeding."

The Interactive Theory of Breastfeeding derived from King's Conceptual System ${ }^{(9)}$ encompasses the concrete event of breastfeeding with the required generality for contexts of primary or higher levels of care. However, it is more concrete than simply a grand theory. Results seem to confirm the need to establish a middle-range theory, because it provides a clinical contribution, but also encompasses the conceptual complexity of breastfeeding. 
Theoretical frameworks help in the organization of care and try to guide actions that favor individuals, in order to recover health through nursing care ${ }^{(21-22)}$. Therefore, it is imperative to assess theories that aim to help in the practice and development of nursing and that systematize it by means of a conceptual basis. There is a progressive number of studies that use theoretical frameworks to ground their findings in several areas of nursing $^{(11)}$. Finally, progress in the study of theories and their use in clinical practice can promote knowledge as the foundation of a structure that guides the conducts of the profession ${ }^{(3-4,11,21-22)}$.

\section{Study limitations}

This theory needs to be tested empirically. However, given its recent proposal, future studies must focus on the theory review, that is, in deepening the understanding of theoretical concepts and their relations. Considering that the method used to create the Interactive Theory of Breastfeeding was essentially deductive, this theory needs to be validated by means of inductive procedures.

\section{Contributions to the fields of nursing, healthcare, and public} policy

The Interactive Theory of Breastfeeding can be a useful tool for clinical practice during the prenatal period, delivery, postpartum period and childcare, with the goal of helping nurses and other professionals of mother and child care to gain knowledge; critical thinking; and the necessary skills and decision-making for the protection, promotion, and support to breastfeeding in a safe and effective manner.

This middle-range theory is a soft-hard technology for the investigation of factors that influence the process of breastfeeding in different settings, in order to enlighten health professionals about the aspects that must be addressed during the care of women, children, and families who are experiencing breastfeeding or who intend to breastfeed.

\section{CONCLUSIONS}

The Interactive Theory of Breastfeeding describes and explains, and probably contributes to predict and prescribe this event by means of the interactive process and the systemic conceptual framework that is concordant with the current models of social determiners of health.

Created deductively for the nursing field, based on King's Conceptual System (1981), and on scientific evidence, this theory is abstract enough to be applied in different social, cultural, political and economic contexts, primarily by nurses but also by other professionals.

The connections between the Conceptual Model of Interactive Open Systems and the concepts of this theory allowed for the establishment of a conceptual and procedural construct, and the expected results for a middle-range theory were achieved. Its possible application to the logic of social determiners of health makes it contemporary and relevant to the Unified Health System (SUS, as per its acronym in Portuguese).

The foundation on a conceptual model that is specific to nursing contributes to the development of nursing science, because the theoretical bases are built by a dynamic process, especially with the development of theories that try to explain and describe the elements related to its practice and research.

\section{FUNDING}

Acknowledgments to the support provided by the Brazilian Federal Agency for Support and Evaluation of Graduate Education (CAPES), number 23038.0091178/2012.

\section{REFERENCES}

1. Alligood MR. Nursing theory: utilization \& application. 5. ed. St Louis: Elsevier Mosby; 2013.

2. Bond AE, Eshah NF, Bani-Khaled M, Hamad AO, Habashneh S, Kataua $\mathrm{H}$, et al. Who uses nursing theory? a univariate descriptive analysis of five years' research articles. Scand J Caring Sci[Internet]. 2011[cited 2016 Oct 25];25(2):404-9. Available from: http:// onlinelibrary.wiley.com/doi/10.1111/j.1471-6712.2010.00835.x/epdf

3. Meleis Al. Theoretical nursing: development and progress. 5. ed. Philadelphia: Lippincott William e Wilkins; 2012.

4. Fawcett J. Contemporary Nursing Knowledge: analysis and evaluation of nursing models and theories. 2nd ed. Philadelphia: F.A. Davis Company; 2005.

5. Lööf-Johanson M, Foldevi M, Rudebeck CE. Breastfeeding as a specific value in women's lives: the experiences and decisions of breastfeeding women. Breastfeed Med[Internet]. 2013 [cited 2016 Oct 25];8(1):38-44. Available from: http://online.liebertpub. com/doi/pdf/10.1089/bfm.2012.0008

6. Primo CC, Nunes BP, Lima EFA, Leite FMC, Pontes MB, Brandão MAG. Which factors influence women in the decision to breastfeed? Invest Educ Enferm[Internet]. 2016 [cited 2016 Oct 25];34(1):198-210. Available from: http://www.scielo.org.co/pdf/ iee/v34n1/v34n1a22.pdf

7. Bomer-Norton C. Breastfeeding: A holistic Concept Analysis. Public Health Nurs[Internet]. 2014 [cited 2016 Oct 25];31(1):88-96. Available from: http://onlinelibrary.wiley.com/doi/10.1111/phn.12047/epdf

8. Mulder P. A Concept Analysis of Effective Breastfeeding. J Obst Gynec Neon Nurs[Internet]. 2006[cited 2016 Oct 25];35(3):332-9. Available from: http://www.jognn.org/article/S0884-2175(15)34375-6/pdf

9. King IM. Toward a theory for nursing: systems, concepts, process. New York: Delmar Publishers; 1981. 181p. 
10. Walker LO, Avant KC. Strategies for theory construction in nursing. 4.ed. USA: Pearson; 2005. 227p.

11. Rosa LM, Sebold LF, Arzuaga MA, Santos VEP, Radünz V. Referenciais de Enfermagem e produção do conhecimento científico. Rev Enferm UER][Internet]. 2010 [cited 2016 Oct 25];18(1):120-5. Available from: http://www.facenf.uerj.br\%2Fv18n1\%2Fv18n1a21.pdf

12. Marmot M, Allen JJ. Social determinants of health equity. Am J Public Health[Internet]. 2014[cited 2016 Oct 25];104(S4):S517-S519. Available from: https:/www.ncbi.nlm.nih.gov/pmc/articles/PMC4151898/

13. Geib LTC. Fréu CM, Brandão M, Nunes ML. Determinantes sociais e biológicos da mortalidade infantil em coorte de base populacional em Passo Fundo, Rio Grande do Sul. Cienc Saúde Colet[Internet]. 2010[cited 2016 Oct 25];15(2):363-70. Available from: http://www.scielo.br/pdf/csc/v15n2/v15n2a11.pdf

14. Foley W, Schubert L, Denaro T. Breastfeeding experiences of Aboriginal and Torres Strait Islander mothers in an urban setting in Brisbane. Breastfeed Rev. 2013; 21(3):53-61.

15. Rocha NB, Garbin AJl, Garbin CAS, Moimaz SAS. O ato de amamentar: um estudo qualitativo. Physis[Internet]. 2010 [cited 2016 Oct 25];20(4):1293-305. Available from: http://www.scielo.br/pdf/physis/v20n4/a12v20n4.pdf

16. Nabulsi M. Why are breastfeeding rates low in Lebanon? a qualitative study. BMC Pediatr[Internet]. 2011[cited 2016 Oct 25];11:75. Available from: http://bmcpediatr.biomedcentral.com/articles/10.1186/1471-2431-11-75

17. Boucher CA, Brazal PM, Graham-Certosini C, Carnaghan-Sherrard K, Feeley N. Mothers' breastfeeding experiences in the NICU. Neonatal Netw[Internet]. 2011 [cited 2016 Oct 25];30(1):21-8. Available from: http://www.ingentaconnect.com/content/springer/ jnn/2011/00000030/00000001/art00004

18. Tyler L, Kirby R, Rogers C. Infant feeding practices among Sudanese women now living in regional south east Queensland, Australia. Breastfeed Rev[Internet]. 2014[cited 2016 Oct 25];22(3):13-9. Available from: http://connection.ebscohost.com/c/ articles/99726364/infant-feeding-practices-among-sudanese-women-now-living-regional-south-east-queensland-australia

19. Primo CC, Dutra PR, Lima EFA, Alvarenga SC, Leite FMC. Social networks that support women during breastfeeding. Cogitare Enferm[Internet]. 2015[cited 2016 Oct 25];20(2):426-33. Available from: http://revistas.ufpr.br/cogitare/article/view/37453/25554

20. Prates LA, Schmalfuss JM, Lipinski JM. Social support network of post-partum mothers in the practice of breastfeeding. Esc Anna Nery Rev Enferm[Internet]. 2015[cited 2016 Oct 25];19(2):310-5. Available from: http://www.scielo.br/pdf/ean/v19n2/en_14148145-ean-19-02-0310.pdf

21. Pickett S, Peters RM, Jarosz PA. Toward a middle-range theory of weight management. Nurs Sci Q[Internet]. 2014 [cited 2016 Oct 25];27(3):242-7. Available from: http://nsq.sagepub.com/content/27/3/242.long

22. Reimer AP, Moore SM. Flight nursing expertise: towards a middlerange theory. J Adv Nurs[Internet]. 2010 [cited 2016 Oct 25];66(5):1183-92. Available from: http://onlinelibrary.wiley.com/doi/10.1111/j.1365-2648.2010.05269.x/epdf 